\title{
Determination of the Quality in Orange Juices Marketed in the City of Cartagena de Indias - Colombia
}

\author{
Diofanor Acevedo Correa ${ }^{\# 1}$, Piedad M. Montero Castillo ${ }^{* 2}$, Raul J. Martelo ${ }^{\# 3}$ \\ \# Faculty of Engineering, Food Engineering program, Research Group NUSCA, University of Cartagena \\ Av. El Consulado, St. 30 No. 48-152. Cartagena de Indias, Colombia \\ * Faculty of Engineering, Research Group in Communications and Informatics Technologies GIMATICA. \\ University of Cartagena \\ 1'diofanor3000@gmail.com, ${ }^{2}$ pmargaritamontero@hotmail.com, ${ }^{3}$ rmartelog@gmail.com.
}

Abstract - The objective of this research was to determinate the quality in orange juices marketed in the city of Cartagena de Indias, Colombia. Analyses of Total Soluble solids (TSS), pH and titulable acidity (TA) were performed, and the amino acid content was also determined in three commercial juices, three artisanal juices and one orange juice as a control sample. $\mathrm{pH}$ values were lower in juices with higher acidity. For individual amino acids, the most prevalent were arginine, serine and proline in the range of (2.87-7.23 $\left.\mathrm{g} \mathrm{kg}^{-1}\right),\left(4.89 \mathrm{~g} \mathrm{~kg}^{-1}\right)$ and $\left(3.82-7.43 \mathrm{~g} \mathrm{~kg}^{-1}\right)$, respectively.

Keyword - Determination of amino acids, soluble solids, acidity, $\mathrm{pH}$.

\section{INTRODUCTION}

Citrus juices have gained a great popularity and represent more than $50 \%$ of the drinks available in international trade. The fruit juice industry has become one of the world's most important agricultural businesses, with trade amounting to $\$ 10$ billion a year and dominated by citrus juice [1]. Orange juice is the most prevalent product processed by the beverage industry and is consumed everywhere due to its high content of ascorbic acid, carotenoids and phenolic compounds, and its high nutritional value and desirable sensory characteristics [2]. One of the most important agricultural enterprises on the planet is the fruit juice industry. Many advantages are associated with the production of this beverage, because the fruits are perishable, their production is seasonal and processing technology allows consumption throughout the year [3].

Fruit juices and concentrates have become valuable semi-finished products, commercial production uses a wide variety of fruits such as apple, peach and grape, but is dominated by orange juice. Fruit juice production is one of the fastest growing industries in the world. Although there are many types of juices available, orange juice is still the most widely produced and consumed. However, this popularity makes orange juice a common target for adulteration and fraud. Food authentication is an increasingly important activity in the food industry, where substitution with cheaper ingredients is enhanced by the potential financial rewards that can be obtained. Knowledge of orange juice constituents is the first step in authenticating this foodstuff. Numerous chemical, physical and microbiological procedures have been proposed to test the quality of the juice. These tests assess the presence of naturally occurring substances, but other compounds such as additives and decomposition products are also measured. In addition, specific chemical parameters can be used to detect adulterations, mainly those based on profile analysis, such as sugars, amino acids, carotenoids, flavonoids, limonoids and others [4].

Many kinds of orange juice adulteration have been documented, because it is a rather complex matrix with an intricate profile of volatile compounds and non-volatile polar compounds. The most common types of adulteration are simple dilution with water, addition of sugar syrup, addition of constituents that are not naturally present in orange juice, such as colorants, addition of cheaper juices from other types of fruits (mainly grapes and apples). The most sophisticated forms of adulteration consist of the use of cheap amino acids such as glycine or glutamic acid or protein hydrolysates, with the aim of increasing the total amino acid content. Several methods have been proposed for qualitative / or quantitative analysis of adulteration of fruit juices, the more established approaches that have been successfully used to determine the authenticity of fruit juices are based on carbohydrate profile, phenols or other organic acids using different techniques such as high-resolution liquid chromatography (HPLC) and gas chromatography (GC) [5].

However, studies on the amino acid profile of orange juice are essentially non-existent. Zhan et al., [6] concluded that the presence of the amino acid proline at a concentration above $25 \mathrm{mg} \mathrm{L}^{-1}$ is indicative of grape products added. Although there are almost no chromatographic analysis results on orange juice amino acid values in the literature, grape juices have been analyzed for many years by this method. The reported proline values for grape juice occupy a wide range depending on the variety of grape juice. However, the minimum and maximum values reported are consistent and grape juice contains a fairly large amount of proline. Long et al., [7] reported with HPLC an average of $797 \mathrm{mg} \mathrm{L}^{-1}$ of proline for 10 well-known grape species used in wine 
production. It is clear that even if a fruit juice that does not contain proline is mixed with grape juice, which contains such high levels of proline, the proline values of adulterated juice will change to much higher values than $25 \mathrm{mg} \mathrm{L}^{-1}$. Taking into account the above, the objective of this research was to determine the quality of orange juice marketed in the city of Cartagena-Bolívar.

\section{MATERIALS AND METHODS}

\section{A. Location of the study}

The juice was made in the laboratories of the Nutrition, Health and Food Quality Research Group (NUSCA) of the University of Cartagena, Colombia. The orange juice was obtained from Valencia variety oranges harvested in January 2017, from the municipalities of María la Baja and Arjona.

\section{B. Preparation of natural orange juice}

The oranges were harvested in January 2017, each fruit was packed with a thin plastic bag and stored in cold storage at $4{ }^{\circ} \mathrm{C}$. 20 oranges from each cultivar were randomly selected, peeled and crushed by a household juicer.

A sample of $10 \mathrm{~kg}$ of oranges, selected according to their ripeness, similar size and without physical damage, was used to make the juice, with a maturity index for fresh fruit of 8.92 according to the ratio ${ }^{\circ}$ Brix/acidity. The oranges were washed with cold water, cut symmetrically in two to be subjected to the juice extraction process by an electric juicer. The fresh juice was filtered to remove excess pulp, then pasteurized at $90{ }^{\circ} \mathrm{C}$ for $1 \mathrm{~min}$. The final juice was filled hot in PET bottles and stored at $-2^{\circ} \mathrm{C}$ prior to analysis. A quantity of juice equivalent to 4.5 $\mathrm{kg}$ was extracted for a yield of $45.12 \%\left(\mathrm{w} \mathrm{w}^{-1}\right)$.

\section{Determination of total soluble solids, $\mathrm{pH}$ and titulable acidity}

The total soluble solids content was determined by digital refractometer (AOAC Method 932.12.). The $\mathrm{pH}$ was determined with a $\mathrm{pH}$-meter (AOAC Method 981.12.). Acidity was calculated using a $\mathrm{NaOH}$ titration of $0.1 \mathrm{M}$ using phenolphthalein as an indicator (AOAC Method 942.15.), the results were calculated as anhydrous citric acid [8].

\section{Determination of aminoacids}

The analysis of amino acids in fruit juices and orange juice was performed by high performance liquid chromatography (HPLC). The juice samples were centrifuged for eight $\min , 2 \mathrm{~mL}$ of supernatant were placed in $10 \mathrm{~mL}$ glass tubes containing $1 \mathrm{~mL}$ alpha-aminobutyric acid and $9 \mathrm{~mL}$ of $6 \mathrm{~N} \mathrm{HCl}$. Each sample was analysed in duplicate. To this end, the methodology described by Peter [9] and Li-Ying et al., [10] was used, modifying some analysis techniques.

\section{E. Experimental design}

A completely random design was made. Three varieties of commercial and three artisanal juices were selected, and an orange juice of the Valencia variety was taken as a control sample, made in the laboratory of the Research Group. Data were tabulated in Microsoft Excel and analyzed in Statgraphics Centurion 16.103.

\section{III.RESULTS AND DISCUSSIONS}

Fruit juice adulterations create serious ethical and economic difficulties. Consumers suffer losses, because they expect standard value juices and a genuine product, and honest manufacturers lose a good portion of their market to the dishonest competitor [11].

Table 1 shows the $\mathrm{pH}$, total soluble solids (TSS) and titulable acidity (TA) analyses. $\mathrm{pH}$ values were within the normal range (3.81-4.31) for this type of juice. As can be seen, the $\mathrm{pH}$ values are lower in the juices that had more acidity, being these values different with orange juice. Studies carried out by Barón and Villa [12] on the quality parameters of Valencia variety oranges, reported that the total soluble solids exceeded $10^{\circ} \mathrm{Bx}$ in all the sampling sites, considering that 80 to $85 \%$ of TSS are sugars in Valencia variety orange; in addition, the $\mathrm{pH}$ varied from 3.4-4.8 and the acidity reached values of $2.33 \%$ of citric acid.

Table 1. Fruit juice amino acids

\begin{tabular}{|c|c|c|c|c|c|c|c|}
\hline Parameters & $\begin{array}{c}\text { Commercial } \\
\text { juice A }\end{array}$ & $\begin{array}{c}\text { Artisanal } \\
\text { juice A }\end{array}$ & $\begin{array}{c}\text { Commercial } \\
\text { juice B }\end{array}$ & $\begin{array}{c}\text { Artisanal } \\
\text { juice B }\end{array}$ & $\begin{array}{c}\text { Commercial } \\
\text { juice C }\end{array}$ & $\begin{array}{c}\text { Artisanal } \\
\text { juice C }\end{array}$ & $\begin{array}{c}\text { Orange } \\
\text { juice }\end{array}$ \\
\hline $\mathrm{pH}$ & $3.85 \pm 0.15$ & $4.22 \pm 0.28$ & $4.15 \pm 0.11$ & $4.18 \pm 0.15$ & $3.73 \pm 0.24$ & $4.11 \pm 0.22$ & $3.83 \pm 0.22$ \\
\hline $\mathrm{TSS}$ & $9.2 \pm 0.22$ & $10.7 \pm 0.33$ & $11.5 \pm 0.21$ & $8.85 \pm 0.27$ & $11.12 \pm 0.11$ & $10.18 \pm 0.28$ & $9.73 \pm 0.54$ \\
\hline $\mathrm{TA} \mathrm{g} \mathrm{L}^{-1}$ & $6.23 \pm 0.18$ & $5.45 \pm 0.26$ & $5.49 \pm 0.42$ & $5.87 \pm 0.31$ & $6.91 \pm 0.17$ & $5.86 \pm 0.39$ & $4,22 \pm 0.43$ \\
\hline
\end{tabular}

Table 2 shows that the amino acids that predominated most in artisanal and commercial juices were arginine, serine and proline, in a range of $\left(2.87-7.23 \mathrm{~g} \mathrm{~kg}^{-1}\right),\left(4.89 \mathrm{~g} \mathrm{~kg}^{-1}\right)$ and $\left(3.82-7.43 \mathrm{~g} \mathrm{~kg}^{-1}\right)$ respectively, being similar to the research carried out by Li-yinng et al, [10], who indicated that the main amino acids in the different orange varieties analyzed were serine $\left(5.08-7.88 \mathrm{~g} \mathrm{~kg}^{-1}\right)$, arginine $\left(3.00-9.66 \mathrm{~g} \mathrm{~kg}^{-1}\right)$ and proline (3.94$8.32 \mathrm{~g} \mathrm{~kg}^{-1}$ ), which represented $79.0 \%$ of the total amino acids, varying according to variety. For example, 
Olinda Valencia reported the highest total amino acid content $\left(31.78 \mathrm{~g} \mathrm{~kg}^{-1}\right)$, followed by Trovita $\left(25.35 \mathrm{~g} \mathrm{~kg}^{-1}\right)$ and Delta Valencia (24.95 $\left.\mathrm{g} \mathrm{kg}^{-1}\right)$. Gómez-Ariza et al., [13] characterized and analyzed amino acids from orange juice. They used fresh hand squeezed juices as a benchmark for the amino acids typically profiled in this food. In this analysis, the amino acid content of commercially produced juices was compared with that of fresh juice. Therefore, the total amino acid content and proline concentration may indicate dilution with water and/or the addition of sugar syrup to commercial juices. The content of aspartic acid, histidine, leucine + isoleucine, methionine, phenylalanine, threonine and tryptophan was similar to orange juice packaged from frozen concentrates and one fresh.

Other amino acids such as arginine, glutamic acid, glutamine, lysine, proline, tyrosine and valine are present at lower concentrations in this commercial juice, while for asparagine and serine these values are slightly higher; it was found that the concentration of proline in hand squeezed juice was higher than in commercial samples, which could confirm the possibility of dilution with water. Some studies reinforce the use of amino acid pattern and concentration in the adulteration of orange juice. In this regard, proline, aspartic acid, serine, asparagine, glutamic acid, arginine and alanine have been proposed as the most abundant amino acids in this juice, which could be used to detect adulterations, these authors confirmed, that proline levels can be used to detect juice over-dilution. The addition of cheaper juices from other fruits such as grapes and apples can be easily detected by observing the presence of asparagine, serine, aspartic acid + arginine and proline. Apple juice has low concentrations of serine, aspartic acid + arginine and proline, grape juice of asparagine and serine.

Therefore, the low proline value could be attributed to an apple juice addition. In addition, low levels of serine and low aspartic acid + arginine may confirm the presence of apple juice in commercial orange juice. Finally, if asparagine and serine have low concentrations, there may be dilution with grape juice.

Table 2. Amino acids in artisanal and commercial orange juices

\begin{tabular}{|c|c|c|c|c|c|c|c|}
\hline $\begin{array}{c}\text { Free amino } \\
\text { acids }\end{array}$ & $\begin{array}{c}\text { Commercial } \\
\text { juice A }\end{array}$ & $\begin{array}{c}\text { Artisanal } \\
\text { juice A }\end{array}$ & $\begin{array}{c}\text { Commercial } \\
\text { juice B }\end{array}$ & $\begin{array}{c}\text { Artisanal } \\
\text { juice B }\end{array}$ & $\begin{array}{c}\text { Commercial } \\
\text { juice C }\end{array}$ & $\begin{array}{c}\text { Artisanal } \\
\text { juice C }\end{array}$ & Orange juice \\
\hline Alanine & $0.48 \pm 0.02$ & $0.49 \pm 0.05$ & $0.75 \pm 0.05$ & $0.45 \pm 0.04$ & $0.71 \pm 0.01$ & $1.34 \pm 0.05$ & $12.85 \pm 0.54$ \\
\hline Asparagine & $0.75 \pm 0.01$ & $0.69 \pm 0.06$ & $0.66 \pm 0.03$ & $0.22 \pm 0.02$ & $0.72 \pm 0.04$ & $0.39 \pm 0.09$ & $13.52 \pm 0.76$ \\
\hline Arginine & $15.01 \pm 0.04$ & $5.25 \pm 0.04$ & $6.44 \pm 0.02$ & $2.87 \pm 0.06$ & $4.35 \pm 0.04$ & $7.23 \pm 0.13$ & $280.12 \pm 1.66$ \\
\hline Serine & $4.89 \pm 0.04$ & $5.15 \pm 0.06$ & $8.87 \pm 0.05$ & $4.98 \pm 0.05$ & $7.65 \pm 0.03$ & $5.12 \pm 0.18$ & $25.81 \pm 0.47$ \\
\hline Proline & $4.52 \pm 0.13$ & $4.97 \pm 0.06$ & $5.95 \pm 0.08$ & $3.82 \pm 0.03$ & $4.77 \pm 0.14$ & $7.43 \pm 0.11$ & $320.45 \pm 1.52$ \\
\hline Cysteine & $0.07 \pm 0.01$ & $0.07 \pm 0.01$ & n. d. & $0.02 \pm 0.00$ & $0.06 \pm 0.03$ & n.d. & $10.23 \pm 0.98$ \\
\hline Glutamine & $0.77 \pm 0.02$ & $0.55 \pm 0.05$ & $0.16 \pm 0.01$ & $0.29 \pm 0.09$ & $0.58 \pm 0.11$ & $0.38 \pm 0.07$ & $110.12 \pm 1.65$ \\
\hline Glycine & $0.16 \pm 0.08$ & $0.07 \pm 0.02$ & $0.13 \pm 0.01$ & $0.15 \pm 0.01$ & $0.15 \pm 0.06$ & $0.16 \pm 0.01$ & $28.22 \pm 0.83$ \\
\hline Histidine & $0.48 \pm 0.01$ & $0.67 \pm 0.08$ & $1.17 \pm 0.05$ & $1.22 \pm 0.08$ & $0.71 \pm 0.01$ & $0.56 \pm 0.04$ & $44.03 \pm 0.67$ \\
\hline Phenylalanine & $0.17 \pm 0.02$ & $0.20 \pm 0.01$ & $0.24 \pm 0.03$ & $0.35 \pm 0.01$ & $0.38 \pm 0.06$ & $0.43 \pm 0.04$ & $130.43 \pm 0.32$ \\
\hline Lysine & $0.13 \pm 0.02$ & $0.16 \pm 0.04$ & $0.05 \pm 0.00$ & $0.19 \pm 0.02$ & $0.29 \pm 0.03$ & $0.14 \pm 0.07$ & $33.15 \pm 0.49$ \\
\hline Leucine & $0.05 \pm 0.00$ & $0.04 \pm 0.01$ & $0.04 \pm 0.01$ & $0.05 \pm 0.00$ & $0.06 \pm 0.01$ & $0.08 \pm 0.00$ & $7.5 \pm 0.08$ \\
\hline Methionine & $0.05 \pm 0.05$ & $0.05 \pm 0.04$ & $0.03 \pm 0.01$ & $0.05 \pm 0.01$ & $0.04 \pm 0.00$ & $0.46 \pm 0.02$ & $11.52 \pm 0.18$ \\
\hline lsoleucine & $0.05 \pm 0.43$ & $0.05 \pm 0.00$ & $0.06 \pm 0.00$ & $0.06 \pm 0.01$ & $0.07 \pm 0.00$ & $0.07 \pm 0.01$ & $15.86 \pm 0.35$ \\
\hline Threonine & $0.26 \pm 0.09$ & $0.23 \pm 0.01$ & $0.25 \pm 0.00$ & $0.21 \pm 0.07$ & $0.29 \pm 0.07$ & $0.25 \pm 0.07$ & $11.23 \pm 0.32$ \\
\hline Tyrosine & $0.27 \pm 0.02$ & $0.14 \pm 0.01$ & $0.28 \pm 0.01$ & $0.35 \pm 0.07$ & $0.27 \pm 0.02$ & $0.46 \pm 0.01$ & $8.23 \pm 0.13$ \\
\hline Valine & $0.19 \pm 0.05$ & $0.17 \pm 0.02$ & $0.22 \pm 0.03$ & $0.21 \pm 0.01$ & $0.24 \pm 0.06$ & $0.35 \pm 0.06$ & $13.58 \pm 0.21$ \\
\hline
\end{tabular}

There is also evidence that there was no adulteration with addition of grape or apple fruit juices, with low values of indicator amino acids (serine and proline) being reported compared to prepared orange juice. Conversely, Asadpoor et al., [3] reported twenty-six samples of various flavored fruit juices showed adulteration levels. Most of these samples were (73\%) less concentrated than stated on the label, and five samples were produced without the use of fruit concentrate. In addition, amino acids such as glutamic acid and lysine and aromatic aromas were most likely added. It seems that in order to obtain economic and financial benefits, some manufacturers are involved in the adulteration of their products, producing a low-quality product rather than real juice. Regulatory agencies need to increase their oversight and use regulations that are more powerful to ensure the authenticity of the quality of fruit juices and to protect public health. Table 3 shows that similar concentrations of asparagine and serine are present in all cases analysed, which denotes the absence of 
adulteration by adding grape juice. On the other hand, proline levels in both commercial juices are lower than in a new one, and can be seen under aspartic acid and arginine in both commercial juices.

The latter is most evident in the case of freshly squeezed oranges, which could be attributed to a dilution of apple packaging juices [13]. Peter [9] stated that individual amino acid levels varied greatly, even between juices of the same variety. Amino acid levels in the orange drink are low compared to orange juices. This is not surprising, as this product has undergone considerable dilution. The dilution of the orange beverage differs according to an order of magnitude depending on the amino acid chosen for comparison with the juices.

Table 3. Amino acid concentrations in apple and grape juice [13]

\begin{tabular}{lcccc}
\hline & \multicolumn{4}{c}{$\operatorname{Aminoacids}\left(\mu \mathrm{g} \mathrm{mL} L^{-1}\right)$} \\
\cline { 2 - 5 } Apple juice & Asparagine & Serine & Aspartic acid + arginina & Proline \\
Grape juice & Trece levels & $30.48-91.44$ & $577.72-2381.58$ & $265.88-819.83 .51$ \\
\hline
\end{tabular}

Tezcan et al., [14] determined amino acids in pomegranate juices, the dominant amino acids of all freshly squeezed pomegranate juices were: serine, proline and alanine in gradually decreasing order. Most amino acid contents, especially the L-proline content of commercial juices reconstituted from concentrates are considerably lower than the amino acid content of natural juices. Amino acids are not inexpensive chemicals, so common artificial additives are added in order to increase the total amino acid content, some inexpensive amino acids such as glycine and glutamic acid and protein hydrolysates would be added to the juices [13].

\section{CONCLUSION}

The amino acids most commonly found in artisanal and commercial orange juice samples were arginine, serine and proline, in the range of (2.87-7.23 g kg-1), (4.89 $\mathrm{g} \mathrm{kg}-1)$ and (3.82-7.43 $\mathrm{g} \mathrm{kg}-1)$ respectively. Apple juices contain a large amount of Asn compared to orange juices. Therefore, this amino acid could be a marker for adulteration of orange juice with apple juice. It could be established that commercial and artisanal juices were not adulterated with the addition of cheap amino acids or protein hydrolysates. It can be inferred that the amount of amino acids and comparison of the sample amino acid profile with the standard values appears to be an indicator of quality control, providing regulatory agencies with a tool that helps to produce healthier juice.

\section{REFERENCES}

[1] G. D'Orazio, A., Cifuentes, andS. Fanali, "Chiral nano-liquid chromatography-mass spectrometry applied to amino acids analysis for orange juice profiling", Food chemistry, vol. 108, no. 3, pp. 1114-1121, 2008.

[2] E.Agcam, A.Akyildiz, andG. A. Evrendilek, "A comparative assessment of long-term storage stability and quality attributes of orange juice in response to pulsed electric fields and heat treatments", Food and Bioproducts Processing, vol. 99, pp. 90-98, 2016.

[3] M.Asadpoor, M.Ansarin, andM. Nemati, "Amino acid profile as a feasible tool for determination of the authenticity of fruit juices",Advanced pharmaceutical bulletin, vol. 4, no. 4, pp. 359-362, 2014.

[4] M.Cerdán-Calero, L.Izquierdo, J. M.Halket, andE. Sentandreu, "Evaluation of minimal processing of orange juice by automated data analysis of volatiles and nonvolatile polar compounds determined by gas chromatography coupled to mass spectrometry", International journal of food science\& technology, vol. 49, no. 6, pp. 1432-1440, 2014.

[5] F.Ammari, L.Redjdal, andD. N. Rutledge, "Detection of orange juice frauds using front-face fluorescence spectroscopy and independent components analysis", Food chemistry, vol. 168, pp. 211-217, 2015.

[6] Y.Zhang, D.Krueger, R.Durst, R. Lee, D.Wang, N. Seeram,and D. Heber, "International multidimensional authenticity specification (IMAS) algorithm for detection of commercial pomegranate juice adulteration", Journal of agricultural and food chemistry, vol. 57, no. 6, pp. 2550-2557, 2009.

[7] D.Long, K. L.Wilkinson, K.Poole, D. K.Taylor, T.Warren, A. M.Astorga, andV. Jiranek, "Rapid method for proline determination in grape juice and wine", Journal of agricultural and food chemistry, vol. 60, no. 17, pp. 4259-4264, 2012.

[8] AOAC - Association of Official Analytical Chemistry. Official methods of analysis.19th ed. Gaithersburg, 2012.

[9] J. C. Peter, "The analysis of amino acids in fruit juices by high-performance liquid chromatography", Journal of the Science of Food and Agriculture, vol. 37, no. 10, pp. 1019-1026, 1986.

[10] N. Li-ying, W.U. Ji-hong, L. Xiao-jun, CH. Fang, W. Zheng-fu, Z.Guang-hua and H.U.Xiaosong,"Physicochemical characteristics of orange juice samples from seven cultivars", Agricultural Sciences in China, vol. 7, no. 1, pp. 41-47, 2008.

[11] A.Stój, andZ. Targoński, "Use of amino acid analysis for estimation of berry juice authenticity",ActaScientiarumPolonorumTechnologiaAlimentaria, vol. 5, no. 1, pp. 61-72, 2006.

[12] R. D.Barón, andA. L. Vlla, "Evolución de los parámetros de calidad de naranja valencia producida en el municipio de Chimichagua, Cesar-Colombia", Temas Agrarios, vol. 18, no. 1, pp. 66-74, 2013.

[13] J. L. Gómez-Ariza, M. J.Villegas-Portero, andV. Bernal-Daza, "Characterization and analysis of amino acids in orange juice by HPLC-MS/MS for authenticity assessment”,AnalyticaChimicaActa, vol. 540, no. 1, pp. 221-230, 2005.

[14] F.Tezcan, S.Uzaşı̧, G.Uyar, N.Öztekin, andF. B. Erim, "Determination of amino acids in pomegranate juices and fingerprint for adulteration with apple juices". Food chemistry, vol. 141, no. 2, pp. 1187-1191, 2013. 